\title{
A Longitudinal Study of Self-Esteem: Implications for Adolescent Development
}

\author{
Mare A. Zimmerman, ${ }^{1}$ Laurel A. Copelard, ${ }^{2}$ Jean T. Thope, ${ }^{3}$ \\ and T. E. Dielnarian \\ Received March 3, 1996; accepred May 4, 1996
}

This study used a cluster analytic approach to identify selfesteem trajectories among adolescents over a four-year period from sixth to tenth grudes $\mathbb{N}=$ 1,160). Four self.esteem trajectories were identified that replicated previous research: (1) consistently high, (2) moderate and rising, (3) steadily decreasing, and (4) consistently low. Female adolescents were more likely to be in the steadily decreasing self-esteem group while male adolescents were more likely to be in the moderate and rising group. African American and white youth were equally distributed across groups. Using repeated measures anolysis, we found that youth with consistently high and moderate and rising self-esteem reported developmentally healthier outcomes in Grade 10 than youth in the other two clusters. Outcomes included susceptibility to peer pressure, school

This study is based on research supported by the National Instimute on Alcohol Abuse and Alcoholism Grant No. AA06324 (John E. Schulenberg, R.I.) and partially supported by the National Institute on Alcohol Abuse and Alcoholism Grant No. AA09026 (Jean T. Shope, P.I.).

${ }^{1}$ Associate Professor, Department of Health Behavior and Health Education, School of Public Health, University of Michigan, 1420 Washington Heights, Ann Arbor, Michigan 48109-2029. Received Ph.D. from University of IHinois. Research interesis include adolescent health and resiliency and empowerment theory. To whom correspondence should be addressed.

${ }^{2}$ Research Specialist, Health Services Research and Development, Veterans Affairs Medical Center, Ann Arbor, Michigan, and doctoral student, Department of Tealth Behavior and Health Education, School of Public Health, University of Michigan. Received M.P.H. from University of Michigan. Research interests inciude adolescent alcohol and substance use, driving behavior, and injury prevention.

${ }^{3}$ Associate Research Scientist, University of Michigan Transportation Research Institute and the School of Public Health Department of Health Behavior and Health Education. Received Ph.D. from Wayne State University. Research interests include adolescent alcohol and substance use, driving injury prevention, and school health promotion.

${ }^{4}$ Retired from the Department of Postgraduate Medicine and Heallk Professions Education, University of Michigan. Received Ph.D. from University of Hawaii. Research interests focused on school-based alcohol and substance use prevention.

117 
grades, and alcohol use. Implications of these results for studying self-esteem and developmental change more generally are discussed.

\section{INTRODUCTION}

Self-esteem is generally regarded as the evaluation that persons make about themselves that expresses a self-judgment of approval, disapproval, and personal worth (Demo and Savin-Williams, 1992; Rosenberg, 1965; Suls, 1989). Researchers also suggest that a universal human desire exists to protect and enhance one's self-worth (Covington, 1984; Maslow, 1970). The role of self-esteem in adolescent development is well documented (Harter, 1990; Suls, 1989). Low self-esteem has been associated with depression (Harter, 1986; Reinherz et al., 1989; Rosenberg, 1965), suicide (Kazdin et al., 1983), delinquency (Bynner et al., 1981; Rosenberg et al., 1989; Wells and Rankin, 1983), substance use (Dielman et al., 1989a; Selnow, 1985; Stacy et al., 1992), and poorer academic outcomes (Barnes and Welte, 1986; Hawkins et al., 1992; Johnston and O'Malley, 1986; Kandel, 1980). Consequently, the successful development of a positive sense of selfworth may help enhance healthy outcomes or protect youth from engaging in problem behaviors.

Much of the research on adolescent self-esteem, however, has been cross-sectional (Demo and Savin-Williams, 1992). Research that has included longitudinal analysis of self-esteem change over time has produced inconsistent results. Demo and Savin-Williams (1992) report that over extended periods of time "there is remarkable consistency and stability to self-concept and overall judgments of self-regard" (p. 135). They found slight increases, however, in self-esteem from ninth to tenth grades using both the Rosenberg and Coopersmith measures and also peer ratings (Savin-Williams and Demo, 1984). Other investigators who have reported changes in self-esteem over time have also found gradual increases from Grades 7 to 12 with no apparent decrease during the adolescent years (McCarthy and Hoge, 1982; Nottelmann, 1987; O'Malley and Bachman, 1983; Rosenberg, 1986; Simmons et al., 1973). Simmons et al. (1973), however, found that when transition from elementary to junior high school included a change in school context, youths' self-esteem tended to decrease during this period. Conversely, when school context did not change between sixth and eighth grades, researchers have found increases in self-esteem (Demo and Savin-Williams, 1983; Simmons et al., 1979).

In longitudinal studies examining change or developmental stability, researchers have focused on average self-esteem scores for all respondents to detect mean change over time. Developmental stability has been studied 
using across-occasion correlations of a single variable measured repeatedly. Correlations of .60 are typically presented as evidence of stability over time (Simmons and Blyth, 1987). Yet, both of these approaches have serious limitations (Hirsch et al., 1993).

Hirsch and DuBois (1991) pointed out that these two approaches may not be sensitive to intragroup variation. Studies of average change over time in a sample cannot determine if evidence of no change is due to no real change, or to the offsetting increases and decreases of individuals in the sample on the variable of interest. Correlational studies of stability are also limited because they typically account for less than half of the variation in the variable of interest (Dusek and Flaherty, 1981; O'Malley and Bachman, 1983). This leaves open the possibility that subgroup differences exist. As a way to address these concerns, Hirsch and DuBois (1991) used a cluster analytic apprcach to identify subgroup variation. They found that youth could be characterized by one of four self-esteem trajectories-consistently high, consistently low, slightly increasing, and steeply decreasing. Their results suggest that self-esteem may be stable over time for some youths, but vary considerably for others.

One goal of this study was to replicate the finding of subgroup variation among self-esteem trajectories reported by Hirsch and DuBois (1991). Like Hirsch and DuBois (1991), the present study also used a cluster analytic approach to examine these trajectories. The sample consisted of over 1000 youth from sixth through tenth grades, almost $14 \%$ of whom were African American. This study builds on Hirsch and DuBois' work in two significant ways. First, the sample was considerably different. They studied 128 youth from a single school district. The sample in this study was larger, included more African American youth, and consisted of youth from several different communities and schools. Hirsch and DuBois (1991) recommended that their study be replicated with a larger, more representative sample. Second, Hirsch and DuBois' time frame for their study covered Grades 6-8, while the current analysis extended through Grade 10.

Another goal of the study was to see if youth with different self-esteem trajectories reported different attitudinal and behavioral outcomes. Several theories attempt to explain adolescent development including a storm and stress model (Offer and Offer, 1977), problem behavior theory (Jessor and Jessor, 1977), and a resiliency model (Rutter, 1987; Zimmerman and Arunkumar, 1994). One reason no single theory fully explains adolescent development may be that adolescents are not a developmentally homogeneous group. Different self-esteem trajectories may correspond with different explanations of youths' response to peer influence, school performance, and engagement in problem behaviors. 
Positive relationships with peers have been associated with enhanced self-esteem (Hirsch and DuBois, 1991; Savin-Williams and Berdt, 1990), and rejection by peers has been associated with low self-esteem (Demo and Savir-Williams, 1992). Youth with low self-esteem may gain peer approval and avoid rejection by conforming to peer norms and yielding to peer pressure. This may help them increase their positve sense of self because they feel validated by their peers.

Researchers have also found that high levels of self-esteem are associated with high levels of academic achievement (Bachman and O'Malley, 1984; Faunce, 1984; Rosenberg et al., 1989; Wylie, 1979). It is quite possible that good grades help youth maintain or develop a positive sense of self. Finally, delinquency (Harter, 1986; Reinherz et al., 1989) and alcohol and drug use have been associated with low levels of self-esteem (Dielman et al., 1989a; Selnow, 1985; Stacy et al., 1992).

In view of this prior research, our hypotheses related to the psychosocial outcomes are as follows:

1. Youth with high levels of self-esteem will be less susceptible to peer pressure over time than youth with low or decreasing levels of seifesteem.

2. Better school grades will be associated with higher levels of selfesteem.

3. Alcohol use, alcohol misuse, and tolerance for deviance will be greatest among those youth with trajectories that indicate decreasing self-esteem.

\section{METHODS}

\section{Sample and Procedure}

The results presented represent secondary analyses conducted on data gathered as part of a large-scale project to develop, implement, and evaluate a school-based alcohol prevention program (Dielman et al., 1989b; Shope et al., 1992). All youth from six school districts in southeastern Michigan were asked to participate. The communities ranged in population size from 7120 to 104,199 . Youth completed questionnaires in sixth, seventh, eighth, and tenth grades. Data used in the current study were collected at the end of each school year for sixth, seventh, and eighth grades, and at the beginning of the school year for tenth grade. Data collection in ninth grade was not funded. Students completed the paper and pencil questionnaires in classrooms. The questionnaires for the four occasions included 
demographic information, alcohol use and misuse, self-esteem, susceptibility to peer pressure, grades, and tolerance for deviance.

The sixth-grade sample size was 2511; however, absence on the day that the survey was administered, and departure from the school district, resulted in a smaller longitudinal sample. The final sample consisted of 1160 youth with data for all four years. This resulted in a $46 \%$ response rate over four years. The final sample included $13.8 \%$ African Americans $(n=160)$ and $82.5 \%$ whites $(n=957)$. The remaining $3.7 \%(n=43)$ self-identified their race as "other." The sample was approximately evenly divided by sex (males $=585$; females $=575$ ). Sample sizes for different analyses were smaller than the total four-year sample because of missing data, but no systematic differences across analyses were found. All students in the sample experienced school transition from elementary to junior high school between the sixth and seventh grades. In addition, all youth moved from junior high school to high school between eighth and tenth grades.

\section{Measures}

\section{Self-Esteem}

Self-esteem was assessed using a shortened version of Coopersmith's self-esteem scale (Coopersmith, 1967; Dielman et al., 1984). Kokenes (1978) conducted a factor analysis of the original scale and identified four substantive domains represented in the measure: global, school, peers, and family. Dielman et al. (1984) shortened the original scale to 17 items during pilot testing using factor analytic techniques. The shortened version included items from all four domains: 6 global items, 4 school items, 3 peer items, and 4 family items. Sample items included the following: "Do you like the way you are?" "Are you proud of your school work?" "Do kids your age like you?" "Do you get a lot of attention at home?" Also, responses for the 17-item scale were dichotomized (yes $=1 /$ no $=0$ ) to present youth with a forced choice. Item responses were summed to create a scale with a range of $0-17$. Internal reliability of the measure was .73 in sixth grade, and .77 in seventh, eighth, and tenth grades.

\section{Susceptibility to Peer Pressure}

Measures from Rachal et al. (1975) and Davies and Stacey (1972) were used to develop a measure of susceptibility to peer pressure (Dielman et al., 1987). The 7 items in the scale used a 4-point response scale (no, probably not, probably, yes). A sample item is, "If your best friend is skipping 
school, would you skip too?" The iterns also included other areas such as drinking alcohol and smoking cigarettes. Cronbach alphas for Grades 6, 7, 8 , and 10 were $.79, .84, .82$, and .79 , respectively. The sample means for susceptibility to peer pressure were $10.20(S D=3.55)$ in sixth grade, 12.15 $(S D=4.56)$ in seventh grade, $13.82(S D=4.87)$ in eighth grade, and 14.90 $(S D=4.83)$ in tenth grade.

\section{School Grades}

Youth were asked to report their usual grades. The nine response categories for this item were: mostly A's (9), mostly A's and B's (8), mostly B's (7), mostly B's and C's (6), mostly C's (5), mostly C's and D's (4), mostly D's (3), mostly D's and F's (2), and mostly F's (1). The sample means for grades were $7.05(S D=1.57)$ in sixth grade, $6.61(S D=1.59)$ in seventh grade, $6.58(S D=1.64)$ in eighth grade, and $6.75(S D=1.53)$ in tenth grade.

\section{Alcohol Use}

Alcohol use was measured at each occasion with a composite index of beer, wine, and hard liquor use. Each beverage was measured with the same three items: (1) "In the past twelve months, did you drink any (beer, wine, hard liquor)?" (2) "How often have you had a drink of (beer, wine, hard liquor) in the past twelve months?' (3) "When you drank (beer, wine, hard liquor) during the past twelve months, how many (cans, glasses, drinks) did you usually have at one time?" The frequency item (No. 2 above) used a 5-point scale ( $a$ few times a year or less to every day), and the quantity item (No. 3 above) used a 6-point scale (less than 1 to 7 or more).

Responses were recoded, multiplied, and summed across the three beverage types to yield total drinks per week. This value was recoded into a 7-point scale ranging from zero to 6 or more drinks per week. A score of zero indicates no alcohol use, 1.00 represents an average past-year consumption of less than one drink per week, and 6.00 indicates an average of 10 or more drinks per week (Dielman et al., 1989b). The average alcohol use reported by the total sample was $.35(S D=.75), .52(S D=.94), .85$ $(S D=1.24)$ and $1.43(S D=1.65)$ for Grades $6-10$, respectively.

\section{Alcohol Misuse}

Alcohol misuse was measured with 10 items developed from Rachal et al. (1975) and Greenwald (1982), designed to assess problems that youth 
experience as a result of drinking alcohol. The measure included problems with peers (same- and opposite-sex friends), problems with adults (police, parents, teachers), and overindulgence (drank more than planned, sick from drinking). Sample items were as follows: "During the past 12 months, how many times did you get into trouble with your parents because of drinking?" "During the past 12 months, how many times did you get very drunk?" Responses to these Likert-scaled items were primarily bimodal, so each item was recoded to never $(0)$ or at least once (1) and then summed (Dielman et al., 1989b). The total sample mean at each occasion was .48 $(S D=1.04), .66(S D=1.25), 1.10(S D=1.70)$, and $1.55(S D=2.03)$ for Grades $6-10$, respectively. The Cronbach alphas for the misuse scale were $.67, .68, .73$, and .79 for Grades $6-10$, respectively.

\section{Tolerance for Deviance}

A modified version of the tolerance for deviance measure developed by Rachal et al. (1975) was also included. Tolerance for deviance assesses a youth's judgment that specified deviant behaviors are wrong. The five items were Likert scaled (very wrong to not wrong). The summary scale, ranging from 0 to 15 , had Cronbach alphas of $.74, .80, .83$, and .82 in Grades 6-10, respectively. A low score indicates low tolerance for deviance and strong disapproval of the behaviors cited. A sample item was, "How wrong do you think it is to smoke without your parent's permission?" Other behaviors included going to a movie instead of studying for a test, skipping school without an excuse, tearing a page out of a library book, and drinking alcohol before age 21. The sample means for tolerance for deviance were $2.43(S D=2.55)$ in sixth grade, $3.72(S D=3.14)$ in seventh grade, $4.83(S D=3.48)$ in eighth grade, and $6.08(S D=3.53)$ in tenth grade.

\section{Data Analytic Procedure}

Data were analyzed in four stages. First, we conducted attrition analyses comparing youth with all four years of data and youth who did not have complete longitudinal data. Second, a cluster analysis of the raw selfesteem data for all four years was performed to explore the possibility of different self-esteem trajectories within the sample. Thus, each youth had four data points-self-esteem scores in Grades 6, 7, 8, and 10-that were entered in a cluster analysis. Cluster analysis is a statistical procedure that classifies respondents by the pattern or profile defined by their responses on specific variables (e.g., self-esteem scores from four waves of data). The 
profiles may differ in shape or scale. A difference in shape for longitudinal data on the same variable might indicate that one respondent has similar values on all measures over tine (a flat line) while another respondent might have successively increasing values on all measures over time (a sloped line). A difference in scale occurs when an individual has consistently higher scores as compared to another individual.

As suggested by Aldenderfer and Blashfield (1984), two randomly divided subsamples (approximately a 50\% split) were analyzed separately to cross-validate the cluster solutions. Then, the total sample was clustered using initial centroids set to the weighted averages of the centroids obtained from the split-haif analyses. This procedure was used for the total sample analysis because the split-sample results provided an empirical basis for defining initial parameters. The number of youths who were assigned to different groups in the split and total sample analyses were then examined to assess cluster stability. Two procedures were used to determine the number of clusters to retain. These were (1) inspecting the change in values of the proximity coefficients, and (2) examining the theoretical meaningfulness of different solutions (see Aldenderfer and Blashfield, 1984; Everitt, 1980).

Ward's method, which uses squared euclidean distance as a proximity measure, was the clustering technique chosen to identify the initial cluster solution. Ward's method was especially suitable because it raximizes within-group homogeneity and between-group heterogeneity (i.e., defines groups that are highly dissimilar from each other). We also used Ward's method because it does not require specification of the number of clusters as other methods (e.g., $k$-means) typically do. Although the study by Hirsch and Dubois (1991) suggests that a four-cluster solution would be appropriate, we did not wish to constrain our solution based on a single study. In addition, enough differences existed between the studies (e.g., sample, measures) that specification of clusters might not be warranted. Finally, we believed an effort to replicate should not impose the results from earlier work because it would create a biased situation in which similar findings would be more likely.

The third analytic step used chi-square analyses to explore the possibility that sel isted, then a factorial design (e.g., cluster group by race or sex) would be warranted for the next analytic step.

The fourth analytic stage used repeated measures analyses of variance (MANOVA) to examine both main effects for cluster group and interaction effects between cluster group and time (i.e., change over time across cluster groups). We examined main effects for cluster, gender, and time, two-way interactions of cluster and gender by time, and three-way interactions of 
cluster by gender by time. Where significant MANOVA effects were found, post hoc comparisons with Duncan's correction for joint confidence intervals were run to pinpoint group differences. The dependent variables were susceptibility to peer pressure, school grades, alcohol use and misuse, and tolerance for deviance.

\section{RESULTS}

\section{Attrition Avalyses}

No differences were found between attrited students and those with data for all four years for race $\left(\chi^{2}=2.29\right.$; ns) or gender $\left(\chi^{2}=.14 ; n s\right)$. Attrited students reported more alcohol use $(t=4.16 ; p<.01)$, more alcohol misuse $(t=5.79 ; p<.01)$, more susceptibility to peer pressure $(t=$ $3.31 ; p<.01)$, and more tolerance for deviance $(t=3.21 ; p<.01)$ than youth included in the study (all analyses based on sixth-grade data). Attriters also reported lower self-esteem in sixth grade than youth with data for all four years $(t=5.51 ; p<.01)$.

\section{Correlations Across Occasions}

Table I reports the intercorrelations of the self-esteem measures for each study year, and total sample means and standard deviations. The largest correlation among self-esteem measures from one year to the next is .56. The correlations between self-esteem assessments that are two or more years apart range from .29 to .41 and indicate decreasing temporal consistency with increasing passage of time.

Table I. Intercorrelations of sulf-esteem measures, total sample means, and standard deviations for each year ${ }^{t}$

\begin{tabular}{lcccccc}
\hline & Grade 6 & Grade 7 & Grade 8 & Grade 10 & Mean & SD \\
\hline Grade 6 & - & & & & 13.23 & 2.43 \\
Grade 7 & .53 & - & & & 12.92 & 2.66 \\
Grade 8 & .41 & .56 & - & & 12.72 & 2.78 \\
Grade 10 & .29 & .38 & .52 & - & 11.87 & 2.83 \\
\hline
\end{tabular}

${ }^{a}$ All correlations are significant beyond the .01 level. 


\section{Cluster Analysis}

The split-sample analyses resulted in two similar four-group cluster solutions that were theoretically meaningful and distinct. When the total sample was clustered, the same four groups emerged. Group membership was unchanged for $81 \%$ of the sample between the split-half and total-group analyses; instability was noted among those students with consistently high self-esteem and those with moderate and rising self-esteem. The shapes and scales of the self-esteem profiles were similar in all three analyses. Figure 1 depicts the self-esteem trajectory profiles from the total sample and group means for each year.

One group had consistently high ( $n=531 ; 48 \%$ ), one group had moderate and rising ( $n=204 ; 19 \%)$, one group had steadily decreasing ( $n=$ 223; $20 \%$ ) and the fourth group had consistently low self-esteem scores $(n=143 ; 13 \%)$. For the total sample, youths' self-esteem decreased from sixth $(\bar{X}=13.26 ; S D=2.42)$ to tenth grades $(\bar{X}=11.87 ; S D=2.82$; $t[1130]=14.87 ; p<.01)$. A repeated measures analysis of variance on self-esteem scores also indicated that the pattern of self-esteem change over time (group by time interaction) differed across the four trajectory groups $(F[9,3297]=326.53 ; p<.001)$ and that their overall level of self-esteem (main effect) also differed $(F[3,3297]=431.77 ; p<.001)$.

\section{Demographic Differences}

African American and white youths were equally distributed across groups defined by their self-esteem trajectory $\left(\chi^{2}[3]=3.34\right.$; ns). Males and females, however, were not equally distributed across groups $\left(\chi^{2}[3]=27.94\right.$; $p<.01)$. Cell chi-square values indicated that more males $(n=124)$ and fewer females $(n=80)$ than expected were in the moderate and rising self-esteem group; conversely, more females $(n=82)$ and fewer males $(n$ $=61$ ) than expected were in the steadily decreasing group. Subsequent analyses included a gender by trajectory factorial design.

\section{Self-Esteem Trajectories and Longitudinal Measures}

\section{Susceptibility to Peer Pressure}

A self-esteem trajectory by time interaction was found for susceptibility to peer pressure $(F[9,3252]=6.97 ; p<.01)$, but gender by time $(F[3$, $3252]=.23$; ns), and trajectory by gender by time $(F[9,3252]=1.21 ; \mathrm{ns})$ effects were not found. Cluster $(F[3,1084]=30.40 ; p<.01)$ and time 


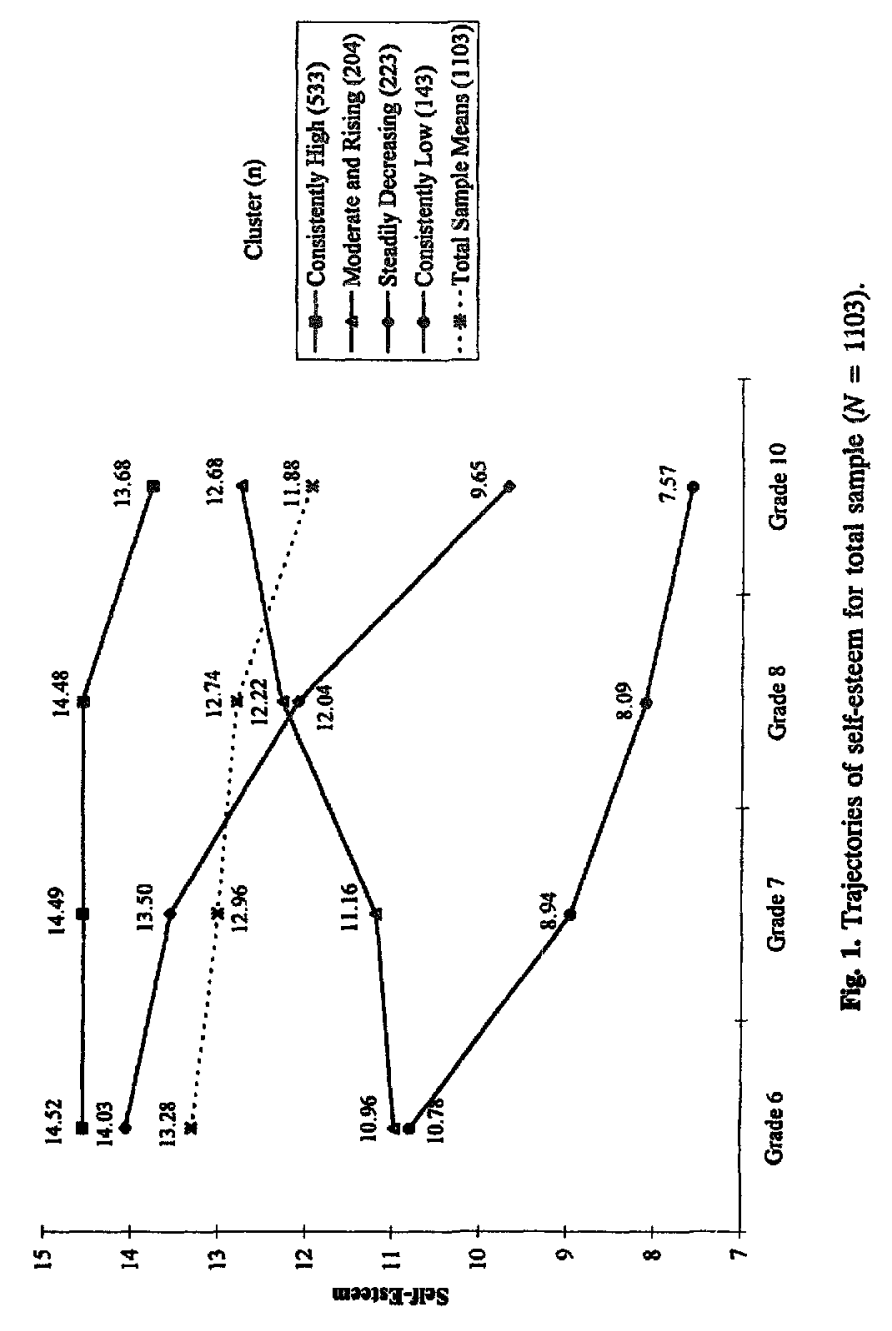


$(F[3,3252]=429.62 ; p<.01)$ main effects were also found. The consistently high self-esteem group scored significantly lower at all occasions than the other three groups $(p<.05)$. All post hoc differences were significant except moderate and rising vs. consistently low in Grades 6 and 7 , moderate and rising vs. steadily decreasing in Grade 8 , and steadily decreasing versus consistently low in tenth grade. Susceptibility to peer pressure rose the least for the moderate and rising group, while the greatest increase over time occurred in the steadily decreasing group. Figure 2 displays the means at all occasions for the four self-esteem groups' susceptibility to peer pressure.

\section{Grades}

A self-esteem group by time interaction for school grades was found $(F[9,2979]=5.37 ; p<.01)$, but the gender by time $(F[3,2979]=.66$; ns) and three-way $(F[9,2979]=.88$; ns) interactions were not significant. Cluster $(F[3,993]=43.22 ; p<.01)$ and time $(F[3,2979]=34.54 ; p<$ .01) main effects were found. Grades decreased from Grade 6 to Grade 8 , with various outcomes in tenth grade. All means were significantly different except for moderate and rising vs. consistently low in sixth and eighth grades, moderate and rising vs. steadily decreasing in eighth grade, and steadily decreasing vs. consistently low in Grade 10, in the same pattern as was seen above with susceptibility to peer pressure. The steadily decreasing group had the greatest drop in grades from sixth to eightin grade, and the consistently high group had the smallest decrease over time. Youth in the moderate and rising group were the only ones to show an increase in grades from Grade 6 to Grade 10. Youth in the steadily decreasing group were the only ones to have grades decrease every year. Figure 3 reports mean school grades over time for the self-esteem trajectory groups.

\section{Alcohol Use}

A three-way interaction (self-esteem trajectory by gender by time) was found for alcohol use $(F[9,2943]=1.97 ; p<.05)$. Cluster group by time interaction was also found $(F[9,2943]=5.22 ; p<.01)$, but no gender by time interaction was found $(F[3,2943]=.63 ; \mathrm{ns})$. Main effects were found for time $(F[3,2943]=228.74 ; p<.01)$, cluster $(F[3,981]=14.17 ; p<$ $.01)$ and gender $(F[1,981]=4.56 ; p<.05)$. Thus average scores differed across cluster and gender groups, and the change in alcohol use over time differed across the cluster groups as well. Initially, male adolescents in the moderate and rising group reported the most alcohol use, but they were surpassed by both males and females in the steadily decreasing and con- 


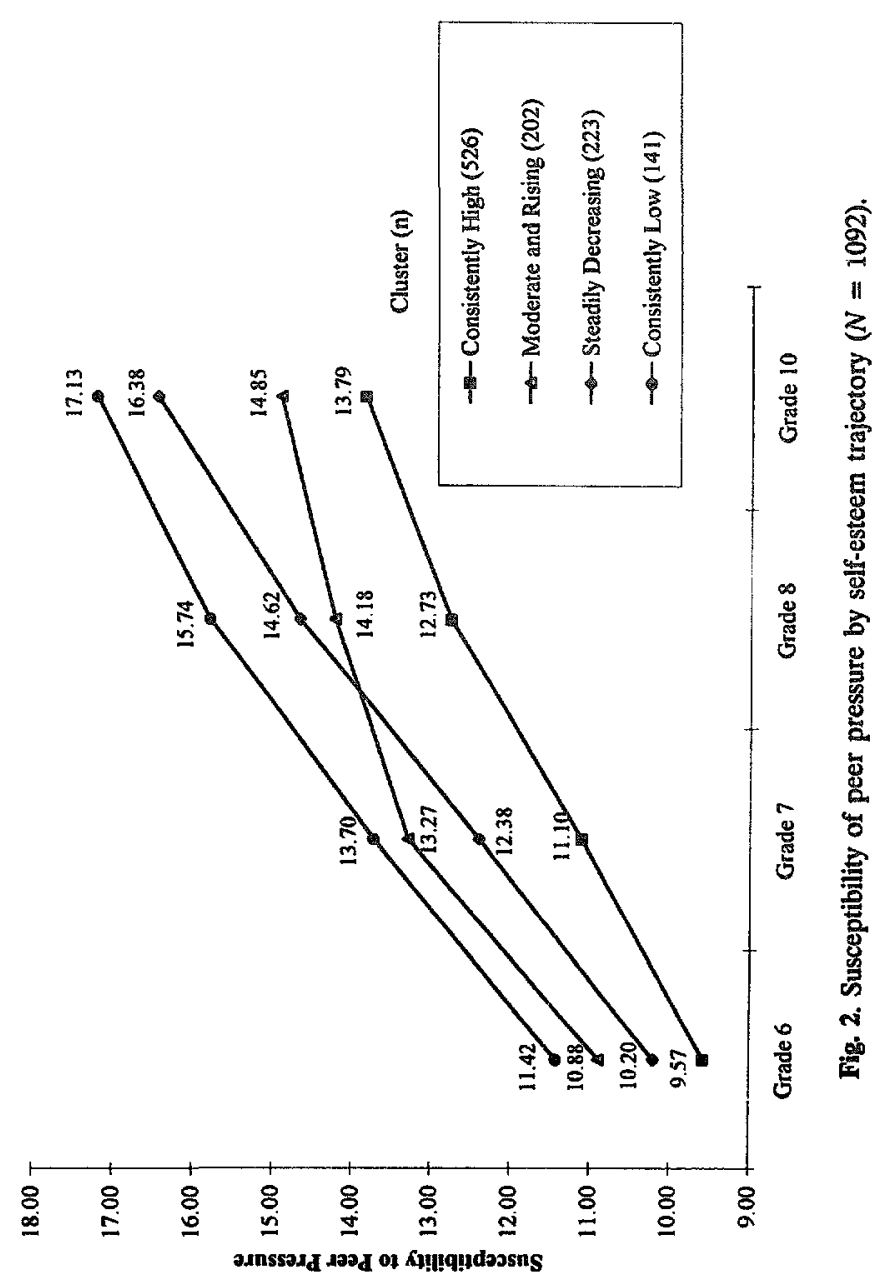




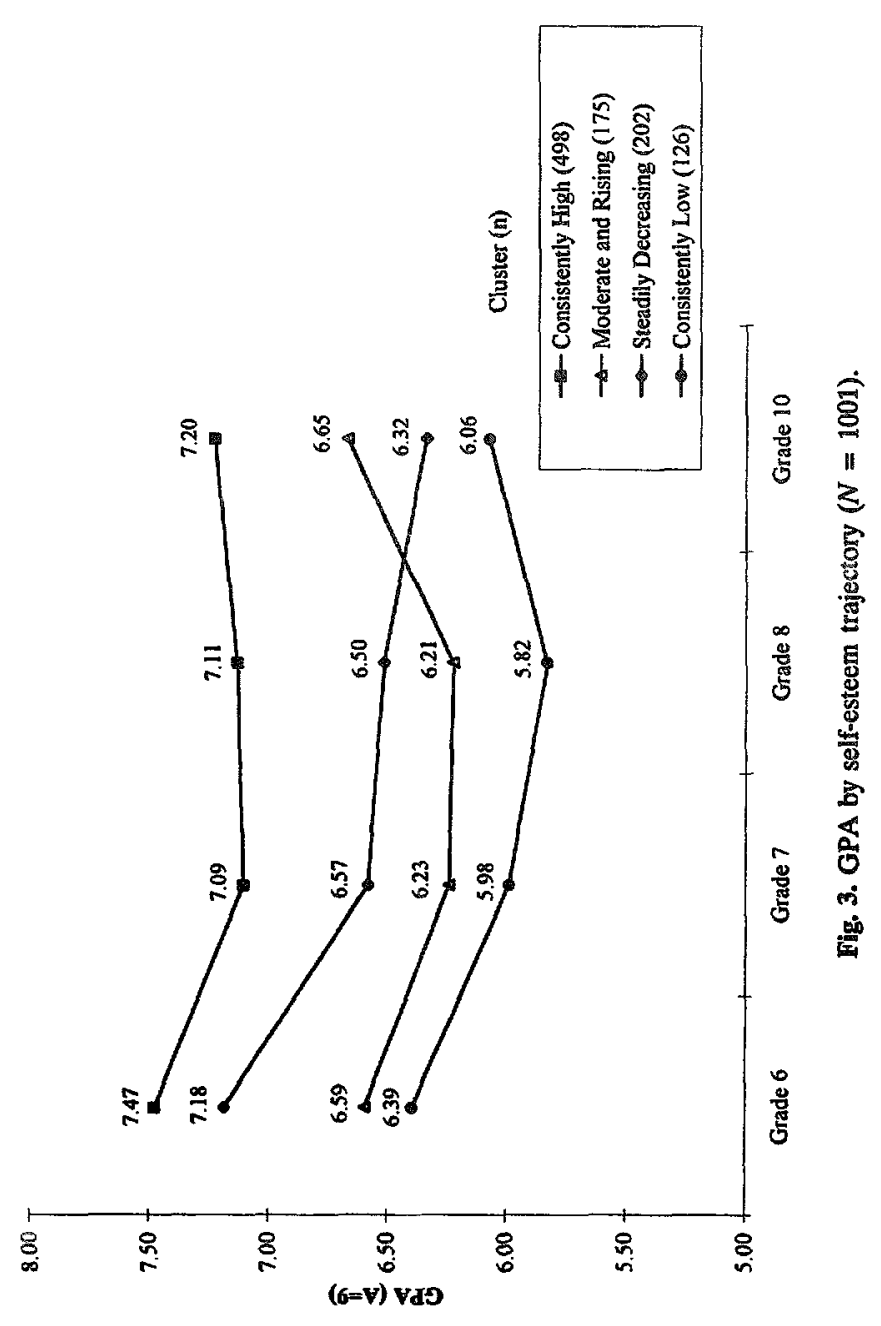


sistently low groups. By the eighth grade, however, male and female adolescents in the steadily decreasing and consistently low groups reported the most alcohol use for their respective sexes. Males in the steadily decreasing group had the greatest increase in alcohol use over time. Females in the moderate and rising group and males in the consistently high group had the least increase in alcohol use over time. Generally, the higher levels of reported drinking occurred among males and in those groups reporting low self-esteem. Figure 4 depicts the means for males and fenales in each group over time.

\section{Alcohol Misuse}

Both self-esteem trajectory by time $(F[9,3150]=5.29 ; p<.01)$ and gender by time interactions $(F[3,3150]=4.76 ; p<.01)$ were found for alcohol misuse. A three-way interaction was not found $(F[9,3150]=.76$; ns). Main effects for time $(F[3,3150]=137.13 ; p<.01)$ and cluster $(F[3$, $1050]=11.11 ; p<.01)$ were also found. Figure 5 reports the group means over time for alcohol misuse. The pattern of results are similar to those for susceptibility to peer pressure and grades. The steadily decreasing group reported the greatest increase in alcohol misuse over time, but in Grade 6 they started at the same level as the consistently high group. Interestingly, the consistently low and moderate and rising groups also started at the same place, but diverged over time. The moderate and rising group reported the smallest increase over time, and the consistently high group reported the lowest levels of misuse at every point in time.

\section{Tolerance for Deviance}

A self-esteem group by time interaction for tolerance for deviance was found $(F[9,3162]=4.94 ; p<.01)$, but no gender by time $(F[3,3162]=$ 1.43 ; ns) or three-way interaction $(F[9,3162]=.60$; ns) effects were seen. Cluster $(F[3,1054]=16.83 ; p<.01)$ and time $(F[3,3162]=380.0 ; p<$ .01) main effects were found. All youth became more tolerant of deviance over time, but higher levels of self-esteem were associated with lower tolerance of deviance. Significant differences $(p<.05)$ were found between the more extreme pairs of means at each occasion. The consistently high group reported the least tolerance for deviance in each grade as compared to all the other groups but the moderate and rising. The pattern of change for each group was similar to that for alcohol misuse. Figure 6 reports the means and standard deviations over time for each group. 


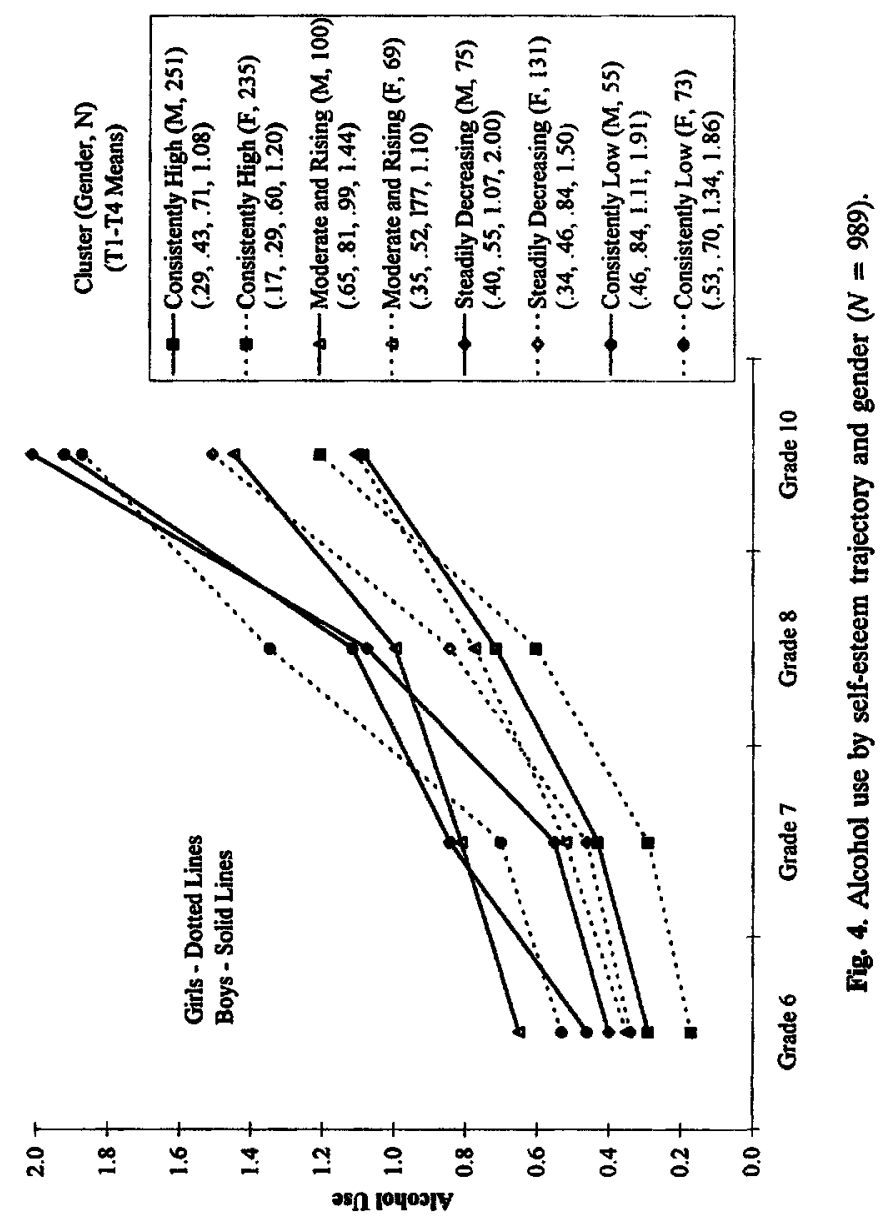




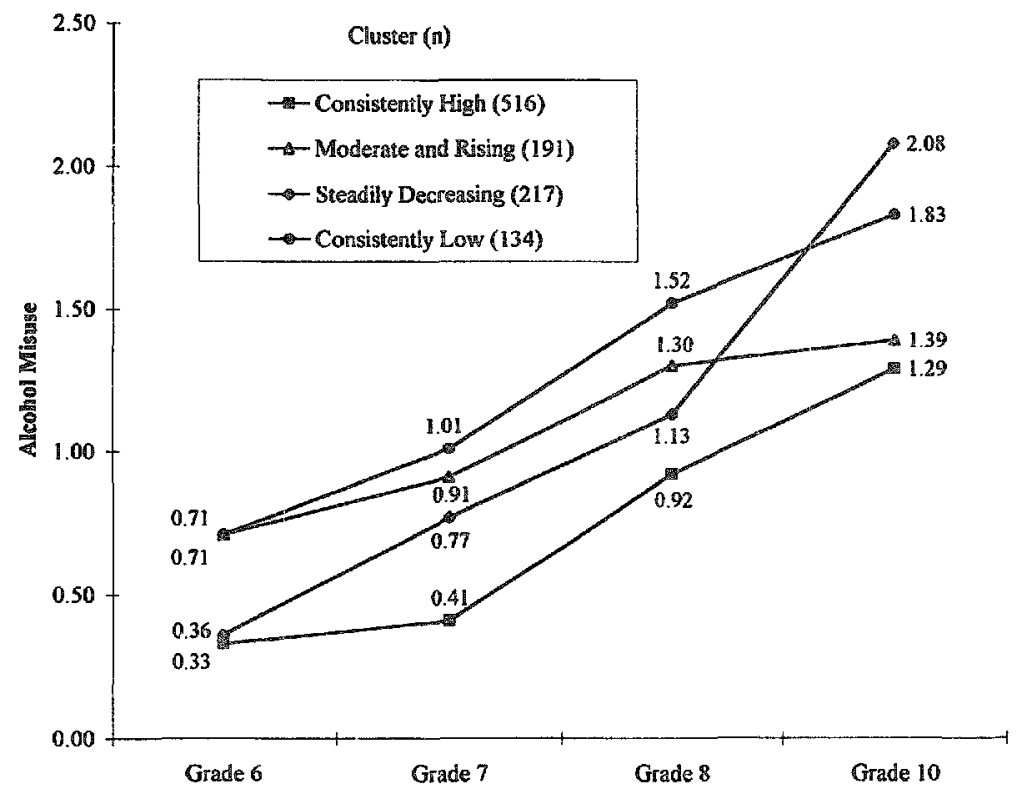

Fig. 5. Alcohol misuse by self-esteem trajectory $(N=3058)$.

\section{DISCUSSION}

The current study replicated findings reported by Hirsch and DuBois (1991). In fact, it is remarkable how similar the self-esteem trajectories were in our study and the Hirsch and DuBois (1991) study in spite of the fact that we used different measures of self-esteem, the samples are quite different, and our clustering algorithm differed. Our largest self-esteem group, as in Hirsch and DuBois (1991), comprised youth with consistently high self-esteem. Similarly, our smallest group included those youth with low self-esteem, although in our sample, this group also displayed steadily falling levels of self-esteem. This difference from the Hirsch and Dubois (1991) study may well be attributed to the fact that our study included self-esteem assessment in tenth grade, but most of the decrease occurred from sixth to eighth grade. It is also possible that this difference is due to the fact that we did not use the same self-esteem measures. Both studies, however, revealed a group of youth who show a steady decline in their self-esteen over time, and a group that show an increase in self-esteem over time. 


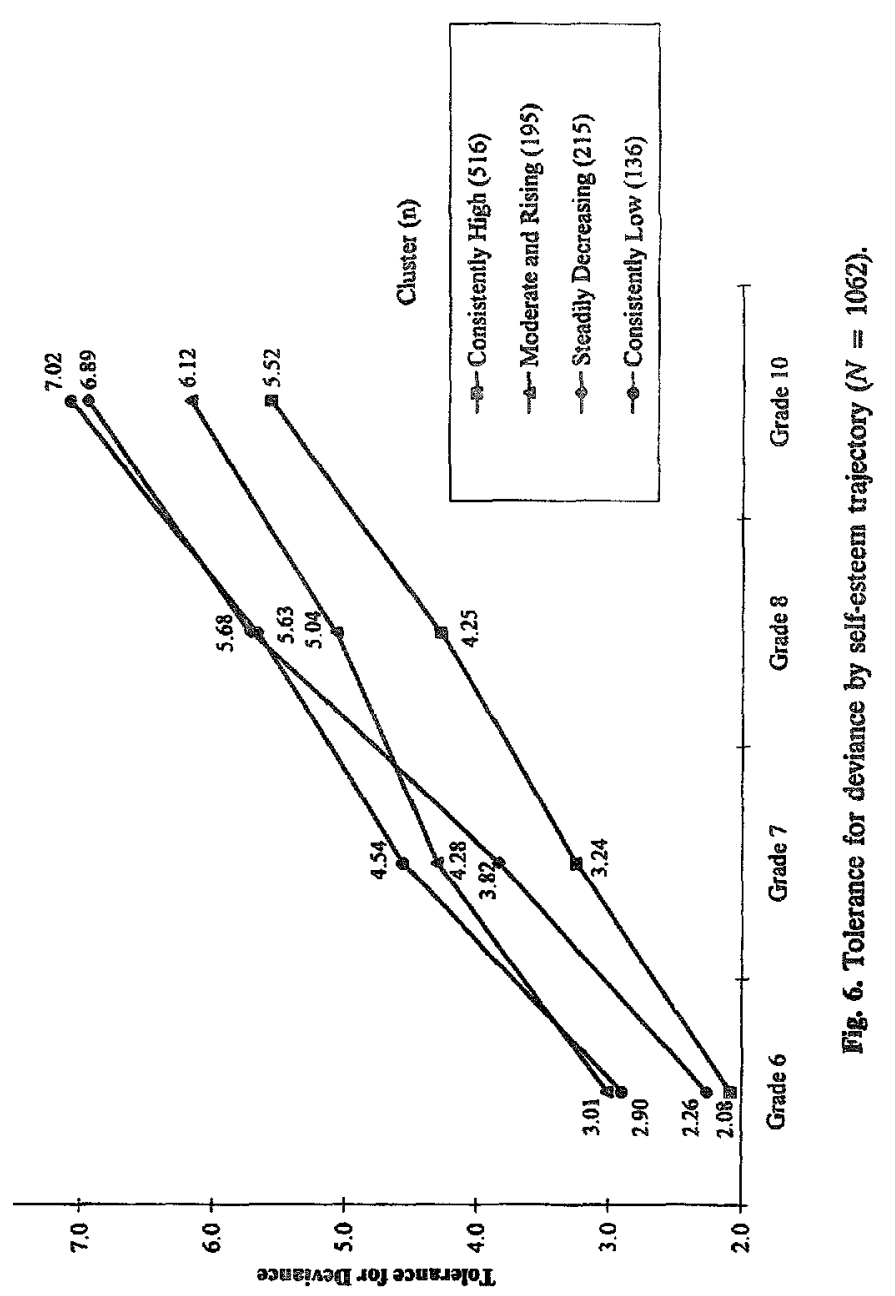


The results also provide additional evidence that whether self-esteem changes over time may not be of primary concern; rather, how individual differences in changing adolescent self-esteem arise may be more vital. Exploration of subgroup variation may be useful for determining how different patterns of change in self-esteem influence and are influenced by other developmental ontcomes.

Revisiting our hypotheses for psychosocial outcomes, the groups differed in both their average score (main effect) and their change in scores over time (Time $\times$ Dependent Variable interaction effect). The following support was found for them:

1. Youth with high levels of self-esteem will be less susceptible to peer pressure over time than youth with low or decreasing levels of self-es. teem. Youth in the consistently high and moderate and rising groups reported less susceptibility to peer pressure over time than youth with consistently low or decreasing self-esteem. The rate of change for susceptibility to peer pressure was the lowest for youth in the moderate and rising group.

2. School grades will be correlated positively with self-esteem trajectories. Grades decreased for all groups through Grade 8, but the steadily decreasing group also reported the greatest decrease in grades over time. The consistently high group not only reported the highest grades at each point in time, but also had the smallest drop in grades over time.

3. Alcohol use, alcohol misuse, and tolerance for deviance will be greatest among those youth with trajectories that indicate decreasing self-esteem, and least among those with high self-esteem. Youth in the consistently high and moderate and rising groups reported less tolerance for deviance, alcohol use, and alcohol misuse over time than youth with consistently low or decreasing self-esteem. The moderate and rising group consistently reported less increase in these measures than the other groups. Main effects for cluster group were also found. The consistently high group reported the lowest levels of each of these measures.

This study suggests that overall trends of self-esteem (either stable, increasing, or decreasing) may not adequately characterize the typical adolescent experience. In fact, the results are not consistent with earlier reports that self-esteem is either relatively stable during adolescence or increases slightly from Grades 7 to 12 (McCarthy and Hoge, 1982; Nottelmann, 1987; O'Malley and Bachman, 1983; Rosenberg, 1986; Savin-Williams and Demo, 1984). Self-esteem in this sample actually declined slightly from Grade 6 to Grade 10. The results, however, are consistent with Alsaker and Olweus 
(1992), who found that self-esteem was relatively stable for short periods of time (up to a year), but changed over longer periods ( 3 years) among early adolescents. Studying how change occurred for subgroups of adolescents enables researchers to distinguish between no change in self-esteem and the countervailing effects of increasing and decreasing scores.

African American and white youth were equally distributed across the self-esteem groups. Although the number of African Americans in the sample was small, it corresponded with the proportion found in the general population. Nevertheless, future research should include a more diverse sample in order to adequately explore possible race differences including Latino, Asian American, and other ethnic groups. Perhaps more to the point, studying youth from varying socioeconomic backgrounds may be more informative than simply examining race differences. Our results are consistent with previously reported gender differences (Eccles, 1984; Simmons and Blyth, 1987). More female adolescents reported decreasing selfesteem trajectories than male adolescents and vice versa for increasing self-esteem. This seems to support findings by Eccles and Midgley (1990), who indicated that females were more likely than males to report a decline in self-esteem as a consequence of school transition. Youth in our sample actually experienced two school transitions during the course of the study.

The longitudinal analyses suggest that self-esteem trajectory was related to alcohol use differently for male adolescents than for female adolescents. Female adolescents in the consistently high self-esteem group had a level of increase in alcohol use similar to that of females in the steadily decreasing group. Yet, males in these two groups were very different in their use over time. The timing of alcohol use increase among adolescents with low or decreasing self-esteem also differed for males and females. Females had their largest jump in Grade 8, while males' largest jump occurred in Grade 10. Females may use alcohol to maintain high self-esteem in their social context, while males may use alcohol to cope with their decline in self-esteem. These interpretations are cautiously made, however, because we did not examine the causal direction among the variables studied.

The results suggest that a single model to describe adolescent development may inhibit the discovery of meaningful differences among adolescents. Findings from youth whose self-esteem steadily declines over time may support a storm and stress model (Offer and Offer, 1977) of adolescence because they may not be effectively negotiating developmental experiences. A storm and stress model, however, may not be applicable to youth with consistent self-esteem trajectories (either high or low). Youth with consistently low self-esteem appear to fit a problem behavior model (Jessor and Jessor, 1977) in which adolescents exhibit multiple deleterious 
behaviors and beliefs (e.g., alcohol use and misuse, low grades, susceptibility to peer pressure).

Youth with either consistently high or rising self-esteem may fit a resiliency model (Rutter, 1987; Zimmerman and Arunkumar, 1994) wherein they develop the skills and psychological resources necessary to cope with stressors experienced as part of their adolescence. For this group of adolescents, self-esteem may enhance the effects of other psychosocial factors, such as parental nurturance, in preventing detrimental outcomes (e.g., substance abuse). This process has been referred to as a protective/protective mechanism (Brook et al., 1992). Alternatively, self-esteem may be part of a risk/protective mechanism (Brook et al., 1992) wherein the protective factor (e.g., self-esteem) helps limit the potential negative effects of a risk factor (e.g., family discord, peer pressure).

The interaction effects found for trajectory and time for all dependent variables suggest a protective role of self-esteem. Every group experienced an increase in susceptibility to peer pressure, for example, but the steadily decreasing self-esteem group reported a faster increase. Self-esteem may help limit the development of susceptibility to peer pressure, which has been found to be a risk factor for problem behaviors (Dielman et al., 1992). Most strikingly, youth with increasing self-esteem also tended to show the greatest improvement or least decline over time for all outcomes measured. Studies that explore the protective-protective and risk-protective mechanisms among youth with rising or consistently high self-esteem would be useful.

The most striking effects of self-esteem change over time were found for the two groups that had either improving self-esteem (moderate and rising) or declining self-esteem (steadily decreasing). These two groups often started at a similar point, but went in the opposite direction for every dependent variable assessed except grades. The results of grades, however, for these two groups were even more divergent. The two groups essentially switched places in high school for grades. These results suggest that efforts either to prevent and stabilize decreasing self-esteem or to build self-esteem may have vital effects on other outcomes for youth. Hirsch et al. (1993) suggest that how self-esteem change relates to other negative outcomes may be useful for understanding risk. This knowledge can then be used to focus resources on the group most likely to experience problem behaviors.

Prevention efforts may also have varying effects for youth with different self-esteem trajectories (Hirsch et al., 1993). Perhaps the notion that one program design fits all is obsolete. One strategy might reach youth with steadily decreasing self-esteem, while a different approach would be more effective for youth with rising self-esteem. Limited resources may be more effectively allocated as a result, taking fewer resources to reach youth 
with rising self-esteem and more resources to reach those on a downward trajectory.

\section{Study Limitations}

One limitation of the study is that self-report data were the only source of data available for analysis. This raises the unresolved issue of shared method variance among the study variables. A related issue is that our tolerance of deviance measure refers to an attitude about deviance and not deviant (or delinquent) behavior. Future research could benefit from including behavioral measures for several problem behaviors such as delinquency and assaultive violence.

Another limitation is that the split-half and total sample cluster solutions had only $81 \%$ agreement. This raises some question about the stability of the self-esteem trajectories identified in the study. The limitation is offset by several points. First, the shapes of the profiles in the two split-half and final solutions were similar. Although some youth had profiles that were borderline to two groups, the underlying patterns of self-esteem remained the same. Second, most disagreement between solutions occurred between the consistently high and moderately increasing groups. In other words, the movement from one group to another was subtle, and probably a result of the clustering algorithm. Ward's method adjusts the group centroid as new cases are assigned and then uses that new information for assignment of the next case. Thus, respondents with values that are between two centroid series may be assigned to different groups depending on who was entered before them. Third, the cluster solution replicated previous research. The similarity of the split-half and final trajectories to the Hirsch and DuBois (1991) findings (which resulted from a different clustering algorithm) suggests that the longitudinal self-esteem profiles found in this study accurately characterize self-esteem patterns in early to middle adolescence.

Finally, the attrition analyses suggest that our data are not representative of all youth in the schools studied. That attriters reported lower self-esteem also had the effect of reducing membership in trajectories characterized by a low initial self-esteem level. The omission of some youth with low self-esteem in sixth grade may have made it more difficult to replicate trajectory results due to restricted range for defining self-esteem groups. In addition, less variance in the trajectory groups may also have made it more difficult to detect group and time differences, although the results suggest otherwise because they replicate previous research.

In sum, we concur with conclusions drawn by both Hirsch and DuBois (1991) and Simmons and Blyth (1987) that longitudinal analysis will benefit 
from innovative and diverse methods, such as the one reported here. A cluster analytic approach may provide useful information about developmental change. It allows for the possibility of discovering intergroup variation in a sample and avoids problems associated with studying average change over time. This strategy provides an opportunity to identify how different models of adolescent development may be applicable for different youth. Consequently, the search for a global model of adolescent development may be modified to an analysis of which model is more appropriate for a given subset of youth.

\section{ACKNOWLEDGMENTS}

The authors would like to thank David DuBois and the anonymous reviewers for their helpful and thoughtful comments on earlier drafts of this article.

\section{REFERENCES}

Aldenderfer, M. S., and Blashfield, R. K. (1984). Cluster Ana'ysis. Sage, Newbury Park, CA. Alsaker, F. D., and Olweus, D. (1992). Stability and global self-evaluations in early adolescence: A cohort longitudinal study. J. Res. Adolesc. 47: 123-145.

Bachman, J. G., and O'Malley, P. M. (1984). Black-white differences in self-esteem: Are they affected by response style? Am. J. Sociol., 90: 624-639.

Barnes, G. M., and Welte, J. W. (1986). Patterns and predictors of alcohol use among 7-12th grade students in New York State. J. Studies Alcohol 47: 53-60.

Brook, J. S., Whiteman, M., Cohen, P., and Tanaka, J. S. (1992). Childhood precursors of adolescent drug use: A longitudinal ana'ysis. Genet. Social Gen. Psychol. Monogr. 118: 195-213.

Bynner, J. M., O'Malley, P. M., and Bachman, J. C. (1981). Self-esteem and delinquency revisited. J. Youth and Adolesc. 10: 407-441.

Coopersmith, S. (1967). The Antecedents of Self-Esteem. W. H. Freeman, San Francisco.

Covington, M. (1984). The motive for self-worth. In Ames, R., and Ames, C. (eds.), Research on Motivation in Education, Vol. 1, Student Motivation. Academic Press, New York.

Davies, J., and Stacey, B. (1972). Teenagers and Alcohol: A Developmental Study in Glasgow. Office of Population Censuses and Surveys, Social Survey Division, London.

Demo, D. H., and Savin-Williams, R. C. (1983). Situational and transituational determinants of adolescent self-feelings. J. Personal Social Psychol. 44: 824-833.

Demo, D. H., and Savin-Williams, R. C. (1992). Self-conce;t stability and change during adolescence. In Lipka, R. P., and Brinthaupt, T. M. (eds.), Self-Perspectives Across the Life Span. State University of New York Press, New York.

Dielman, T. E., Campanelli, P. C., Shope, J. T., and Butchart, A. T. (1987). Susceptibility to peer pressure, self-esteem, and health locus of control as correlates of adolescent substance abuse. Health Educat. Quart. 14: 207-221.

Dielman, T. E., Kloska, D. D., Leech, S. L., Schulenberg, J. E., and Shope, J. T. (1992). Susceptibility to peer pressure as an explanatory variable for the differential effectiveness of an alcohol misuse prevention program in elementary schools.J. School Health 62: 233-237. 
Dielman, T. E., Leech S. L., Lorenger A. T., and Horvath W. J. (1984). Health locus of control and self-esteem as related to adolescent health behavior and intentions. Adolescence. 19: 935-950.

Dielman, T. E., Shope, J. T., Butchart, A. T., Campanelli, P. C., and Caspar, R. A. (1989a). A covariance structural model test of antecedents of adolescent alcohol misuse and a prevention effort. J. Dnig Educat. 19: 337-361.

Dielman, T. E., Shope, J. T., Leech, S. L., and Butchart, A. T. (1989b). Differential effectiveness of an elementary school-based alcohol misuse prevention program by type of prior drinking experience. J. School Health 59: 255-263.

Dusek, J. B., and Flaherty, J. F. (1981). The development of self-concept during the adolescent years. Monogr. Society Res. Child Develop. 46: (Serial No. 191).

Eccles, J. (1984). Sex differences in achievement patterns. In Sonderegger, T. (ed.), Nebraska Symposium on Motivation (Vol. 32). University of Nebraska Press, Lincoln.

Eccles, J., and Midgley, C. (1990). Changes in academic instruction and self-perception during early adolescence. In Montemayer, R., Adams, G. R., and Gullotta, R. P. (eds.), From Childhood to Adolescence: A Transitional Period? Sage, Newbury Park, CA

Everitt, B. (1980). Cluster Analysis. Halsted, New York.

Faunce, W. A. (1984). School achievement, social status, and self-esteem. Social Psychol. Quart. 47: 3-14.

Greenwald, M. A. (1982). Minimizing Alcohol Problems and Smoking: Final Report Year II. University of Pittsburgh, Pittsburgh, PA.

Harter, S. (1986). Cognitive-developmental processes in the integration of concepts about emotions and the self. Social Cogn. 4: 119-151.

Harter, S. (1990). Self and identity development. In Feldman, S. S., and Elliott, G. R. (eds.), At the Threshold: The Developing Adolescent. Harvard University Press, Cambridge, MA.

Hawkins, J. D., Catalano, R. F., and Miller, J. Y. (1992). Risk and protective factors for alcohol and other drug problems in adolescence and early adulthood: Implications for substance abuse prevention. Psychol. Bull. 112: 64-105.

Hirsch, B. J., and DuBois, D. L. (1991). Self-esteem in early adolescence: The identification and prediction of contrasting longitudinal trajectories. J. Youth Adolesc. 20: 53-72.

Hirsch, B. J., DuBois, D. L., and Brownell, A. B. (1993). Trajectory analysis of the transition to junior high school: Implications for prevention and policy. Prevent. Human Serv. 10: 83-101.

Jessor, R., and Jessor, S. L. (1977). Problem Behavior and Psychosocial Development: A Longitudinal Study of Youth. Academic Press, New York.

Johnston, L. D., and O'Malley, P. M. (1986). Why do the nation's students use drugs and alcohol: Self-reported reasons from nine national surveys. J. Dnug Issues 16: 29-66.

Kandel, D. B. (1980). Drug and drinking behavior among youth. Ann. Rev. Sociol. 6: 235-285.

Kazdin, A. E., French, N. H., Unis, A. S., and Esveldt-Dawson, K. (1983). Helplessness, depression, and suicide intent among psychiatrically disturbed inpatient children. J. Consult. Clin. Psychol. 51: 504-510.

Kokenes, B. (1978). A factor analytic study of the Coopersmith self-esteem inventory. Adolescence 49: 149-155.

Maslow, A. (1970). Motivation and Personality (rev, ed.). Harper, New York.

McCarthy, J., and Hoge, D. (1982). Analysis of age effects in longitudinal studies of adolescent self-esteem. Develop. Psychol. 18: 372-379.

Nottelmann, E. D. (1987). Competence and self-esteem during transition from childhood to adolescence. Develop. Psychol. 23: 441-450.

Offer, D., and Offer, J. (1977). From Teenage to Young Manhood. New York, Basic Books.

O'Malley, P. M., and Bachman, J. G. (1983). Self-esteem: Change and stability in adolescent self-concept between the ages 13 and 23. Develop. Psychol. 19: 257-268.

Rachal, J. V., Williams, J. R., Brehm, M. L., Cavanaugh, E., Moore, R. P., and Eckerman, W. C. (1975). A National Study of Adolescent Drinking Behavior, Attitudes, and Correlates: Final Report. NIAAA, Rockville, MD.

Reinherz, H. Z., Stewart-Berghauer, G., Pakiz, B., Frost, A. K., Moeykens, B. A., and Holmes, W. M. (1989). The relationship of early risk and current mediators to depressive symptomatology in adolescence. J. Am. Acad. Child Adoles. Psychiat. 28: 942-947. 
Rosenberg, M. (1965). Society and the Adolescent Self-Image. Princeton University Press, Princeton, NJ.

Rosenberg, M. (1986). Self-concept from middle childhood through adolescence. In Suls, J., and Greenwald, A. G. (eds.), Psychological Perspectives on the Self. Earlbaum, Hillsdale, NJ.

Rosenberg, M., Schooler, C., and Schoenbach, C. (1989). Self-esteem and adolescent problems: Modeling reciprocal effects. Am. Sociol. Rev. 54: 1004-1018.

Rutter, M. (1987). Psychosocial resilience and protective mechanisms. Am. J. Orhopsychiat. 57: 316-331.

Savin-Williams, R. C., and Berdt, T. J. (1990). Friendships and peer relations during adolescence. In Feldman, S. S., and Elliott, G. R. (eds.), At the Threshold: The Developing Adolescent. Harvard University Press, Cambridge, MA.

Savin-Williams, R. C., and Demo, D. H. (1984). Developmental change and stability in adolescent self-concept. Develop. Psychol, 20: 1100-1110.

Selnow, G. W. (1985). Using a stratified approach in substance intervention and prevention programs among adolescents: An empirical analysis. J. Drug Educat. 15: 327-341.

Shope, J. T., Dielman, T. E., Butchart, A. T., Campanelli, P. C., and Kloska, D. D. (i992), An elementary school-based alcohol misuse prevention program: A follow-up evaluation. J. Studies Alcohol. 53: 106-121.

Simmons, R. G., and Blyth, D. A. (1987). Moving Into Adolescence: The Impact of Pubertal Change and School Context. Aldine de Gruyter, New York.

Simmons, R. G., Blyth, D. A., Van Cleave, E. F., and Bush, D. M. (1979). Entry into early adolescence. Am. Sociol. Rev. 44: 948-967.

Simmons, R. G, Rosenberg, F., and Rosenberg, M. (1973). Disturbance in the self-image at adolescence. Am. Sociol. Rev. 38: 553-568.

Stacy, A. U., Newcomb, M. D., and Bentler, P. M. (1992). Interactive and higher-order effects of social influences on drug use. $J$. Health Social Behav. 33: 226-241.

Suls, J. (1989). Self-awareness and self-identity in adolescence. In Worell, J., and Danner, F. (eds.), The Adolescent Decision-Maker. Academic Press, New York.

Wells, E. L., and Rankin, J. H. (1983). Self-concept as a mediating factor in delinquency. Social Psychol. Quart. 46: 11-22.

Wylie, R. C. (1979). The Self Concept: Theory and Research on Selected Topics, Volume 2. University of Nebraska Press, Lincoln.

Zimmerman, M. A., and Arunkumar, R. (1994). Resiliency research: Models, issues, and policy implications. Social Policy Rep. 8: 1-18. 